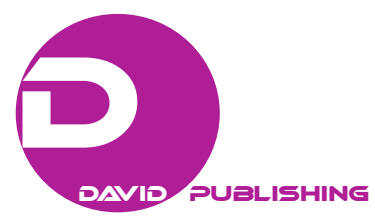

\title{
A New Security Concept: Liquid Security
}

\author{
Sait Yilmaz \\ Başkent Universitesi, Ankara, Turkey
}

\begin{abstract}
International institutions and understanding of security formed after the Second World War is increasingly becoming inefficient to deal with the necessities of security in our time. Moreover, the increase of the non-state actors and their influence on security led the way to new arguments that highlight individual security instead of state security such as "right of retention" which is a dispute between the Westphalia system and the liberal order. The possibility to provide security in all national or international levels with the understanding and the institutions of the past is diminishing. We now face a variety of challenges, both old and new, as well as a variety of opportunities to help shape conditions and events that will work both for us and for others. In essence, we have a "paradigm gap" and we recognize that the nature of international politics is a complex for the exercise of power and influence. In a world of continuing diversity, mistrust, and uncertainty, it is likely that the search for a more cooperative global society is likely to remain in conflict with the powerful pressures which exist for state and other political communities, to look after what they perceive to be their own sectional, national, or regional security against threats form without and within. Whether and how greater international and global security can be achieved, still remains the hardest nut of international politics to crack. Within this study, by introducing the concept of "liquid security" for the first time in terms of finding security solutions to the scope and variety of the 21 st century, it is focused on the fundamental basis of the probable new international order and security understanding. Fundamental principle as the basis of liquid security is to ensure a cooperative global society in a standard and fair security system.
\end{abstract}

Keywords: security, liquid security, world order, hegemony, emancipation

\section{Introduction}

The persistent expansion of the agenda and diversified actors within intensifying structure of the 21 st century require a new security paradigm which will provide a new ontological and epistemological approach. And the purpose of this article is to acquire the theory of "liquid security" to the literature of security which is considered to bring in a new approach to the security concerns. For this purpose the paper is organized in four parts. The first part introduces a methodology based on the seven security methodological questions, and applies this question to the theoretical approach to security. As a result here is introduced the idea of orthodox security. Therefore, this part looks at the alterations in security understanding in the first quarter of the $21 \mathrm{st}$ century and considers the following points: theoretical gaps in current security understanding; questions of multilateralism; challenge between Westphalia and liberal world order; and technological implications for social life and security in the future. The second part explains why we need a new security concept, and it does it in analyzing the foreseen changes in international balance; the increasing vulnerability of international

Sait Yilmaz, Associate Professor, Faculty Member of Political Science and International Relations, Başkent Universitesi. 
security institutions; the need for a sophisticated security model against new threats and risks; and the regionalization/localization of security. The third part unfolds the concept of liquid security and develops the conceptual considerations for liquid security; a model for liquid security; a proposition of a draft model and course of study; and model security solutions. The fourth part of the paper is represented by the conclusion which highlights the fact that the proposed conceptual framework of liquid security refers to a system to ensure monitoring of potential insecurities and respond to them a well-developed and coordinated global and regional institutional system which is disintegrated from national political considerations in a preconditioned international rules and well-designed security pools providing liquidity among them.

\section{Why We Need a New Security Concept}

In the collapse of the Soviet Union and the recent events in Afghanistan, Georgia, Ukraine, or Arab Movements, that "security" has tried to liberate itself from a rigid orthodox interpretation, in which security-military-war were tied together, and to prepare itself to provide an insight in order to secure and face "liquid" threats (Ercolani, 2010, pp. 91-93). Two terms (orthodoxy and liquidity) found an historical position in the period that stretches from 1991 up to present, representing a mirror in which "security" will be reflected. The idea of "liquid conflict" calls in a major collaboration between various sectors of our society and members of our society which is always moving and changing. Because we as human beings are all connected each other as liquids are. We have to start to see to these and future conflicts through the lens of peace, then not win war ("bellum-war", and or "wers-war") but the priority is to win security. When we go back to the Buzan's security sectors theory, the five sectors of security: military, political, economic, societal, and environmental, all of them have to play as a security team. The five sectors can become liquid tools to face liquid threats with the purpose not to win a war or all the other variants, but with the aim to win security, because these liquid threats infiltrate societies, and borders or walls do not stop them. But again the problem remains on the credibility of the message and of the impartiality of actors as recent events in Libya or Ukraine had show to the world that other actors are capable in picking up a script and play the pantomime.

\section{Foreseen Changes in International Power Balance}

The very collapse of superpower competition has irrevocably transformed the contours of great power relations (Kennedy-Pipe, 2000, p.77). The global diffusion of power makes the international system highly unpredictable and heightens the sense of uncertainty that decision makers confront when shaping policies (Kay, 2006, p. 343). In 2030s, a multi-polar world can be predicted and competition between great powers in the realm of controlling raw material resources, market share and technology domination will continue. The level and nature of this competition will be the determinant key to international stability. Because the alliance of the 21 st century will be dependent on certain targets, in the form of various coalitions rather than ideological coalitions or dogmatic bases, however it will not bring a lasting peace and stability. There is the necessity of supra-state structuring about the settlement of security issues, with much variable content and quality rather than great powers and power politics. Neither in the past nor today or tomorrow, even a super power like the USA has been competent enough or will be competent in tackling global security problems. This is a matter of both budget and power capacity, and even a matter of legitimacy. We require mechanism acting beyond political intent just like a world police, which is permanent, acquiring automation, within certain rules instead of the great powers, alliance and coalitions of the past. This system will prevent, intervene and rehabilitate the 
international, transnational and fluent security problems indicating the danger of expansion, by liquid security apprehension with the rules of engagement specified in advance and modular ability pool.

\section{Increasing Vulnerability of International Security Institutions}

Why would a leading state surrounded by a world of weaker states want to establish multilateral institutions? The answer is that institutional agreements can lock other states into a relatively congenial and stable order. The institutions help create a more favorable and certain political environment in which the leading state pursues its interests. For many years now, the UN has struggled with the question of what place supra-national regional organizations should and could take in achieving UN goals. Since the 1990s, the UN has worked in highly politicized and militarized environments, from Bosnia to East Timor. In many of these settings UN and NGO humanitarian actions were used as a substitute for unsuccessful political and military interventions. In the midst of bitter intrastate conflicts, the traditional separation between military and humanitarian operations disappeared. Consequently, in the eyes of local combatants, the UN became closely identified either with one side or the other, or with the intervening forces (Loescher, 2004, p. vii).

It is also evident that the role of the new security in responding to chronic sources of instability and conflict is essential to international and regional security. In regard to a capability-legitimacy "bargain" between the global and regional organizations, the future for the new security is clouded, dependent upon developing effective "hybrid" arrangements with regional institutions and upon its capacity to overcome the erosion of its role as the sole legitimizing agency for the use of force in the international order (Brian, 2004, pp. 227-244). International and regional institutions also would need to be reformed to meet the challenges and shoulder more of the burden. The role of the new security in trying to set norms is itself an issue and probably will complicate efforts by the global community to come to an agreement on a new set of rules. We need new global security order and institutions eliminated from power competitions and national interests.

\section{Need for a Sophisticated Security Model Against New Threats and Risks}

In the 21 st century, strife between nation-state and power, though still remains central, a wider frame of security and insecurity emerged. These factors can be determined as: the bad moving as fast as the good at global scale, the increase of the influence of the new actors like the business world and non-governmental organizations, the necessity for new rules and arrangements in the field of economic security. With the contemporary security challenges (Table 2), security dilemma dynamics threaten to heighten fear, provoke mistrust, and close down possibilities for building cooperation and trust. The international order will be in greater flux beyond 2020 than at any point since the end of the Second World War. They highlight various "switching points" that could shift developments onto one path or the other. Global problems, from violent extremism to worldwide recession to climate change to poverty, demand collective solutions, even as power in the world becomes more diffuse. They require effective international cooperation, even as that becomes harder to achieve (Clinton, 2010). Recognition of the inadequacy of state and state-to-state politics in assuring the security of their people advocates a liquid system: the immediate creation of supranational agencies assuming control from governments of certain, clearly defined political areas.

The governing capacity of states, however, will determine whether and to what extent conflicts actually occur. Internal conflicts are often particularly vicious, long-lasting, and difficult to terminate. Many of these conflicts generate internal displacements and external refugee flows, destabilizing neighboring countries. Some internal conflicts, particularly those that involve ethnic groups straddling national boundaries, risk escalating 
into regional conflicts. At their most extreme, internal conflicts can result in failing or failed states, with expanses of territory and populations devoid of effective governmental control. Such territories can become sanctuaries for transnational terrorists (such as Al-Qaeda or Islamic State of Iraq and al-Sham (ISIS) at global) or for criminals and drug cartels (such as in Colombia). The Middle East is unlikely to be the only battleground in which this struggle between extremists and reformers occurs. Southeast Asia also has been increasingly a theater for terrorism. The open demonstration of nuclear capabilities by any state would further discredit the current nonproliferation regime, cause a possible shift in the balance of power, and increase the risk of conflicts escalating into nuclear ones.

\section{Regionalization/Localization of Security}

The realm of international relations comprises today not only states and global regimes such as the United Nations, but also many international organizations with a mandate in regional peace and security. Although these organizations, such as the African Union (AU), the Organization of American States (OAS), the EU, or the North Atlantic Treaty Organization (NATO) have made significant headway over the last decade and are regarded as key actors in the prevention and resolution of conflicts, their role remains under-studied. The dramatically altered geopolitical landscape also presents a huge challenge for the international system as well as the security organizations. The majority of threats and security problems are primarily regional rather than local, national, or global (Tavares, 2009, pp. 3-4). With the international system itself undergoing profound flux, some of the institutions that are charged with managing global problems may be overwhelmed by them. Regionally based institutions will be particularly challenged to meet the complex transnational threats posed by terrorism, organized crime, and Weapon of Mass Destruction (WMD) proliferation. Weak governments, lagging economies, religious extremism, and youth bulges will align to create a perfect storm for internal conflict in certain regions. The number of internal conflicts has boomed with suppressed ethnic and nationalistic strife.

Global security can be enhanced through widely accepted and shared global ethics and good global governance. In line with trend toward regionalization there is a political logic that certain aspects of governance should be undertaken at the global level, since they simply cannot satisfactorily be carried out at even the regional inter-state level (Hough, 2004, pp. 236-237). Since decolonization, the regional level of security has become both more autonomous and more prominent in international politics, and that the ending accelerates this process (Katzenstein, 2001). Hegemonic stability implies that peace is the by-product of great power dominance over a region. A particular region might be highly unstable, but a major power dominates, it will remain order based on its own interest. The downside is that smaller states can be subjugated to the will of the larger power. This condition puts pressure on regional great powers to exercise dominance in a way that is acceptable to the smaller states who receive benefits from the collective good of stability (Kay, 2006, p. 33).

\section{Concept of Liquid Security}

To begin with, we recognize the following assumptions. Firstly, the Westphalia state system has been persistent, and cannot be deeply transformed in a near future. Secondly, our perception of the system can be changed, and is being changed, allowing for the understanding of more cooperative relations among states. Thirdly, in a nutshell, if every state develops new security concepts and follows proper security policies, even though we still live in a Westphalia state system, conflicts and wars among states can be avoided, while a 
greater stability and peace can be accomplished. Fourthly, international relations (IR) theories tend to reach some consensus. In fact, it is more important for theory development to identify these points of agreement rather than to focus on divisions in research works. Moreover, what emerges from this critical literature is that: (1) The globalization process has eroded the classical concept of power tied to the idea of the nation-state; (2) The concepts of security and insecurity have followed the same evolution of the society which has moved from "defence society" (the Cold War period) to "security society" (the post-Cold War period) and "risk society" (Beck, 1992; 2002; 2006) (the post 9/11 period); and (3) The very essence, form and modalities of war have been changing in the last years.

\section{Conceptual Considerations for Liquid Security}

By this time, the concept of "Liquid Security" is used for various purposes inclusive of a variety of disciplines such as information assurance, preventive and digital security, transportation security, crime control, finance and banking. As for the liquid security hypothesis that we are trying to develop in this study, it is not based upon anything solid, but is a new institutional approach that stresses liquidity of security instead of the long termed and stable security understanding of the past. Liquid security is the high-speed securitization model to provide liquidity for the settlement of the contemporary security issues that emerge or are likely to emerge, in accordance with the pre-determined intervention arrangements and along with temporary force and capability combinations where global, regional and local components are put to use. Basic factors that determine the liquid security at this point is the necessity to find solution to the consisting threat or risks in the shortest time and to attain new concept and institutionalization for the regional wipe out. Securitization is most efficiently done by institutions that isolate default risk and create homogeneous securities. Liquid security rejects state-centered traditional security understanding and collaborations, however, takes care of the in-state sovereignty and territorial integrity of the states.

Actors/Power. Multilateralism implies a relationship based on rules rather than power, with states agreeing that behavior on a certain issue should be governed by shared principles, rules, and norms, regardless of individual interests and circumstances (Caporaso \& Keeler, 1993, pp. 53-54). Of the many global issues that would be best managed through multilateral cooperation, a significant number are environmental in nature (Richard, 2002, pp. 65-66). Because of the truly global nature of these issues, the actions or inaction of every country affect the well being of all countries and peoples, and no country is able to address these issues alone. The states seem to be less and less capable of dealing with the challenges of globalization. To achieve a new security structure both global and regional level, questions of bureaucracy and global government can be resolved through thoughtful design and support of new security actors. The introduction of such bodies to international security is not intended to challenge the sovereign power of states, but rather to achieve through cooperation those things that no state can achieve on its own.

Geographical/Regional Approach. As regionalization becomes widely noticeable in the field of security, a new study will have to be commenced concerning the definition of the borders of Regional Security Complexes (RSCs). The particular definition must comprise geographical proximity, regions suffering from security problems, provision of liquidity and deployment requirements of the regional institutions, according to the demand of the countries; however, countries must not be obliged to security regions where they do not feel at ease. For such a study, Figure 2, depicted by Buzan, can be a reference. In order to qualify as an RSC, a group of states or other entities must possess a degree of security interdependence sufficient both to establish 
them as a linked set and to differentiate them from surrounding security regions. The patterns of amity and enmity are influenced by various background factors such as culture, religion, and geography, but to a large extent they are path-dependent and thus become their own best explanation. The historical legacy of the units in the RSC and the way conditions the principal security actors and the agenda they generate.

RSCs are durable rather than permanent patterns. The relative weights of the domestic, regional, interregional, and global levels, and of the securitizing versus desecuritizing trends. RCSs have an element of core-periphery with a major centre of gravity and a relatively minor appendix (Buzan \& Waever, 2006, p. 475). Table 4 shows the sample indicators for the regional custodianship. Most states historically have been concerned primarily with the capabilities and intensions of their neighbors. Process of securitization and thus the degree of security interdependence are more intense between the actors inside such complexes than they are between actors inside the complex and those outside it (Buzan \& Waever, 2006, p. 4).

Time/Liquidity. The security problems of the Cold War which are difficult to solve and require a length of time are now replaced by liquid, onoff security issues. Hereafter, instead of searching solutions that takes decades, security models will be put into use consisting fast and timely solutions within liquid security understanding. Because such solutions give rise to lesser cost and lesser resource loss, precautions such as early forewarning, rapid reaction, pre-determined engagement and intervention rules, and ready capability pool become compulsory. Regional structures in question, commencing from pre-crisis (peace) conditions, accomplish functions such as pursuing probable security problems, evaluating, concluding, bringing precaution and bringing normalization, will also acquire tasks like carrying out the removal (sweeping) functions. Table 1 shows the differences of traditional and liquid security.

To achieve security, we have to admit cooperative and pursue multilateral strategies, because threats are not limited to one country and cannot be effectively dealt with by a single country. Zero-sum game has been replaced by positive-sum game in the major reasoning. Win-win situations can be achieved. We have to reach a consensus on multi-polarity in power distribution among nations, interdependence, and various institutions to make the world more stable and peaceful than ever. We all can benefit from the current world. The process of securitization is essentially open, and subject to influence by a host of factors. RSCs offer a conceptual framework that classifies security regions into a set of types, and so provides a basis for comparative studies in regional security.

\section{A Model for Liquid Security}

On the basis of liquid security understanding, the utilization of force and capabilities that are constituted in a regional pool against the threat, risk and security problems of various qualities are included fluently and in time. Bringing the basis for the strategy to the forefront stipulates desecuritization, to overcome the problems before they become a security issue, and to settle the security problems that develop prior to folding into political characteristics before it serves to some specific country's manipulative aims by predetermined rules and capabilities. In accordance with the system in question in the first place, a body of rules that are agreed upon have to be generated and honored by all related states and other units. The essence of the fluency of the system is to utilize the capabilities in question transnationally and also consolidate other security regions when needed due to its modular characteristic. The implementations at a global platform, to execute regional functions, procure roles like standardization, the arrangement of assignment definition, administration of the regions and resource and capacity transfer from external regions. In regional level each region will have its own 
security organization and within the global standard implementations will determine their own accomplishment rules. In this context, operational concepts and capabilities will be developed according to its own peculiar security problems.

Table 1

Traditional \& Liquid Security

\begin{tabular}{|c|c|c|}
\hline Parameter & Traditional & Liquid \\
\hline Power & $\begin{array}{l}* \text { Long term alliances } \\
* \text { Hegemonic implications } \\
* \text { Western oriented } \\
* \text { Hard power heavy } \\
* \text { National defense savings }\end{array}$ & $\begin{array}{l}\text { * Capability Building } \\
\text { * Multi-polar environment } \\
\text { * Regional considerations } \\
\text { * Smart power compositions } \\
\text { * Regional force HQs/pools }\end{array}$ \\
\hline Geography & $\begin{array}{l}* \text { Global projection } \\
* \text { Continental Security Zones }\end{array}$ & $\begin{array}{l}\text { * Regional flash points } \\
\text { *Adjustment of zones based on securitization rules }\end{array}$ \\
\hline Time/Liquidity & $\begin{array}{l}* \text { Long duration } \\
* \text { Fixed/low velocity }\end{array}$ & $\begin{array}{l}\text { * Short \& Fluctuating } \\
\text { * Liquidity in security }\end{array}$ \\
\hline Threats/Risks & * Stated sourced military (conventional/ nuclear) & * Transnational or regional security concerns \\
\hline Interest/Mission & $\begin{array}{l}\text { * Deterrence \& wars (decisive/limited etc) } \\
\text { * Peacekeeping/nation building /humanitarian } \\
\text { aids } \\
* \text { Bulky crisis management }\end{array}$ & $\begin{array}{l}\text { * Instant interregional and intraregional solutions } \\
\text { * Police and civilian tasks thru soft power } \\
\text { mechanism } \\
\text { * Security radars }\end{array}$ \\
\hline $\begin{array}{l}\text { International } \\
\text { Framework/Institutions }\end{array}$ & $\begin{array}{l}\text { * Weak universal bodies } \\
\text { * Western dominancy abusing UN system } \\
\text { * NGOs and other civilians for national agendas }\end{array}$ & $\begin{array}{l}\text { * Shift to regional orgs } \\
\text { *Regional focus under strict global rules } \\
\text { * New approach to integrate them from local to } \\
\text { global }\end{array}$ \\
\hline
\end{tabular}

Inside the generic scenarios to be prepared, related to each potential security matter a pool will be organized for force and capability required and the contribution of the regional countries will be requested to the particular pool. The arrangements made will cover preventive and corrective measures at all phases in the manner to prevent the threat before the situation becomes graver under the discipline of the crisis management. Dealing with a lot of security issues regionally and transnationally will give rise to dissolving (diminishing) the existing deterrent and permanent defensive forces held in hand for security problems and defense expenditures in the budget to move to more productive spending items. Also, settlement of the security concerns all over the region will put direct restrictions to the amount of force that the countries will retain and a new agreement linked to disarmament will gain admission much easier. To hold such a system in disposal at an optimum sufficiency besides a well-calculated risk management demands managing the time factor, that is promptness efficiently. In the case of establishing inconsistent relations between security settlements and resources, the result will give rise not only to disaster but may also lead to lose the value of the outcome gained, leading to a waste of an important amount of resource . 
Table 2

The New Security Institutions

\begin{tabular}{|l|l|l|}
\hline Organization & Subsidiary & Function \\
\hline Global Security Council & Secretariat & $\begin{array}{l}\text { Application of the Global Constitution and } \\
\text { maintain regional applications when necessary }\end{array}$ \\
\hline & Crisis Management Organization & $7 / 24$ crisis management \\
\hline & Global Tribunal & $\begin{array}{l}\text { Supervising/recommending in the practice of the } \\
\text { Constitution and solving unsettle issues of regional } \\
\text { courts }\end{array}$ \\
\hline $\begin{array}{l}\text { Regional Security } \\
\text { Complexes }\end{array}$ & Global security modules & $\begin{array}{l}\text { Global force and capability pools(provides } \\
\text { inter-regional liquidity ) }\end{array}$ \\
\hline & Crisis Management Organization & $\begin{array}{l}\text { Main security frame in security issues in } \\
\text { trans-governmental and beyond }\end{array}$ \\
\hline & Regional Courts & 7/24 crisis management \\
\hline & Regional Security Modules & $\begin{array}{l}\text { Main venue for the solution of problems, apolitical } \\
\text { and standard legal settlements }\end{array}$ \\
\hline States & Regional Research and Long Term Planning & $\begin{array}{l}\text { Regional force and capability pools; early } \\
\text { warning, intelligence, operational forces and } \\
\text { abilities, Non-governmental Organizations/NGOs }\end{array}$ \\
\hline & Police force & $\begin{array}{l}\text { Research/policy developing study related to } \\
\text { regional security problems }\end{array}$ \\
\hline
\end{tabular}

\section{Proposition of a Draft Model and Courses of Study}

In the core of the liquid security model, apart from the states' own issues, the rest are the settlement of beyond-state and trans-state security matters dependent on global regulations, without regional adjustments and intervention of the states. The generated unpatriotic (cosmopolitan) security modules will have the characteristics of a pool dependent on the characteristics of the region and consisting the aforethought forces and capabilities to the extent of the presumptive threats and risks. Global and regional regulations that administer these pools will not be under the control of states, but in the form of an independent international authority. In liquid security system, keeping the state sovereignty and the territorial integrity untouched, for the settlement of beyond-state/ trans-state security issues, in the framework of universal rules and implementations, security liquidity is activated by providing the mediation of impartial international organizations as well as the mediation of the forces and capabilities within the modular pool. This liquidity will be provided for structures between global, regional and state, utilizing inter-state and outer state military forces will be pulled down to minimum level and the danger of recoursing to combat and violence will be removed. Related to the structures of global and regional security comprised, the associated states will make stationary contributions according to the level of their national income, and the particular contribution will not give the right to intervene to these states. Adjustments will be made for the control and development of the budget.

The institutions that will work under the description of a forethought and standard methods and rules, hierarchically composed are sequenced below in Table 2 . 


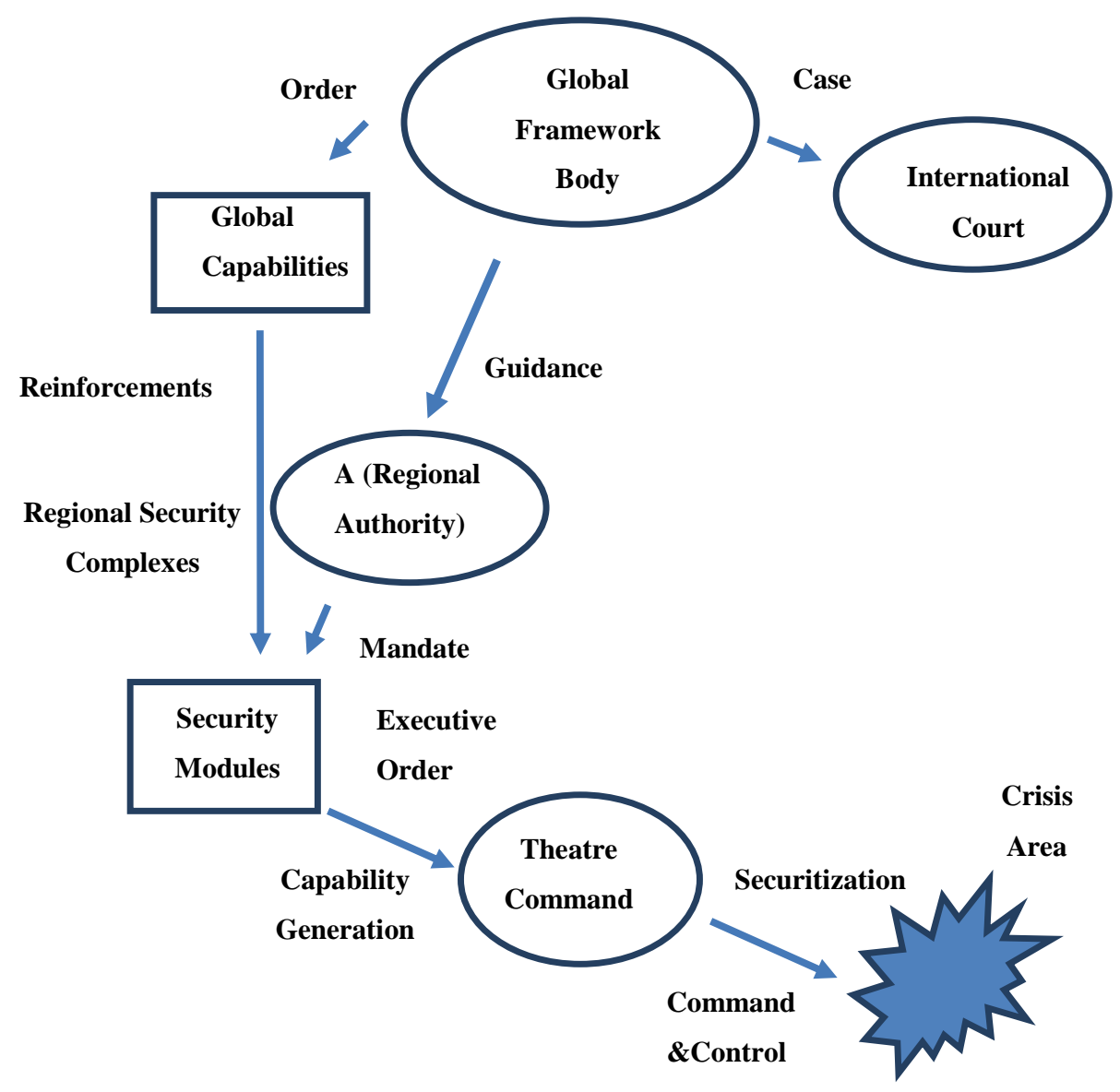

Figure 1. Securitization.

Global Security Council (GSC) will function in the context of universal constitution and security research directory; it will constitute a president and vice president, as well as 9 to 11 members, selected from various regions temporarily. The assignment periods and principles of the assignment will be assessed in the form of a job definition. Global implementations like the World Bank, International Monetary Fund (IMF), Regional Investment Banks, and Information Networks will be under control of GSC. The activities of GSC will be as follows:

(1) to follow up global security issues under the framework of ratified global organizations (such as constitution, directory, instructions), crisis management, early warning, and conflict settlement;

(2) to provide liquidity to regional administration for the settlement of regional troubles and to settle the continuing controversies through universal courts which are the source of final decision;

(3) to implement studies to develop the present application procedures and capabilities;

(4) to develop the necessary institutions and processes for the supervision of functioning of the global security system rightly, fairly and also by means of getting a favorable result.

For the reinforcement of regional security capabilities whenever needed, force and capabilities that have to be guarded on a limited and global means will be provided inside global security modules (Figure 1).

Universal Security Constitution, the particular document that will constitute the only world order and standard regardless of the magnitude, will cover all states and will consist admissible universal adjustments. 
Adjustments have to be global, and applications have to be regional, yet, in the settlement of the problem principles that provide the special considerations (like geographical and historical) have to be assessed between the states. To set up expansion and system of exploitation by means of war and clandestine activities of the countries will be prevented. In the future, targets such as lifting the physical borders entirely between countries, customs union, common exchange (money), central economic planning, and political integration will be reached. Government extensive subjects like national identity, language, and the constitution of a country will be considered as internal affairs of a country.

During the determination of the security regions the voluntarism of the countries, willingness to cooperate, geographical and cultural proximity between countries, the obligations that the security problems bring between the countries will be taken into consideration. Forming asymmetry between the countries in the region will be prevented. To begin with, by settling the difficulties between neighboring countries, long term solutions will be produced to transnational issues. Security settlements will be assessed by Regional Security Council, conformable to the constitution.

The functions of the states in the security area will be in the following manner:

(1) They will content with the settlement of their own internal security problems directed by the police forces, without sovereignty and territorial integrity apprehension.

(2) The settlement of trans-state or supra-state security concerns will be subject to regional implementations and defend their own positions via the related courts.

(3) States can recourse to mastermind. They will collaborate with global and regional security structures, and when necessary and demanded they will reinforce the regional executions.

\section{Conclusion}

The prime argumentation behind the proposal of liquid security model is the security disputes, as a result of the politics that hegemonic powers, under the state-centered Westphalia scheme, exercise in line with their own benefits, creating a constant medium of conflict and threat in the world, global and regional structures that are responsible for the prevention and settlement of these disputes are weak and sanctions inadequate. As the balance between the liquid security method and the asymmetric power variations are prevented by global and regional structures that will be established, the solution to the disputes will be removed from becoming state centered. Thereby, countries will be saved from allocating resource to security matters to a large extent and global disputes like weaponry of mass destruction and terror will be drastically eradicated. While standard and apolitical resolution is brought up for all security matters, hegemonic and ill-minded national ambitions will be prevented. The liquid security in a sense of proposed conceptual work refers to a system to ensure monitoring of potential insecurities and respond to them in a well-developed and coordinated global and regional institutional system disintegrated from national political considerations in a preconditioned international rules and well-designed security pools providing liquidity among them. Liquidity cites the fluency of securitization modules from one region to another and also capability pool to readapt impolitic elements from one case to another in very spectrum of security agenda. Such a new, region-based security structure cannot be realized easily into being. However, opportunities to develop greater international and global security will always exist. It would take years if not decades to develop. Following the development of the draft by the commissions set up by related global organizations and after a number of international conferences, it will reach its final form and will be envisaged to be ready to be open to signatures. 


\section{References}

Beck, U. (1992). Risk society: Towards a new modernity. London: SAGE Publications.

Beck, U. (2002). The terrorist threat: World risk society revisited. Theory, Culture \& Society, 19(4), 29-55.

Beck, U. (2006). Power in the global age: A new global political economy. Cambridge: Polity.

Brian, L. J. (2004). The UN, regional organizations, and regional conflict: Is there a viable role for the UN? In R. Price, \& M. Zacher (Eds.), The UN nations and the global security (pp. 227-243). New York: Palgrave MacMillan.

Buzan, B., \& Waever, O. (2006). Regions and powers: The structure of international security. Cambridge: Cambridge University Press.

Caporaso, J. A., \& Keeler, J. T. S. (1993). The European Community and regional integration theory. University of Pitssburgh. Retrieved January 10, 2017, from http://aei.pitt.edu/7252/1/002711_1.PDF

Clinton, H. R. (2010). Leading through civilian power: Redefining American diplomacy and development. Foreign Affairs. Retrieved from https://www.foreignaffairs.com/articles/north-america/2010-11-01/leading-through-civilian-power

Ercolani, G. (2010). Security: Between orthodoxy and liquidity. In S. Y1lmaz (Ed.), Security and defense perspectives beyond 2010. Istanbul: ISIS Press.

Hough, P. (2004). Understanding global security. Abingdon: Routledge.

Kaplan, R. D. (2000). The coming anarchy: Shattering the dreams of the post-Cold War. New York: Random House.

Katzenstein, P. J. (2001). Re-examining norms of interstate relations in the new millennium. Kuala Lumpur: Paper for the 14th Asia-Pacific Roundtable.

Kay, S. (2006). Global security in the twenty-first century. New York: Rowman \& Littlefield Publishers.

Kennedy-Pipe, C. (2000). Security beyond the Cold War: An introduction. In C. Jones, \& C. Kennedy-Pipe (Eds.), International security issues in a global age. London: Frank Cass.

Loescher, G. (2004). The UN nations and the global security. R. Price \& M. Zacher, (Eds.). New York: Palgrave MacMillan.

Richard, J-F. (2002). High noon: Twenty global problems, twenty years to solve them. New York: Basic Books.

Tavares, R. (2009). Regional security: The capacity of international organizations (global institutions). Abingdon: Routledge. 